\title{
Aplicación clínica de las imágenes de resonancia magnética potenciadas en difusión y tractografía en un niño con holoprosencefalia
}

\author{
Blair Ortiz ${ }^{1,2}$, Diego A. Herrera ${ }^{2,3}$, Sergio Vargas ${ }^{2,3}$ \\ 1 Grupo de Neurología Infantil, Universidad de Antioquia, Medellín, Colombia \\ 2 Grupo de Investigación en Bioelectrónica e Ingeniería Clínica-GIBIC, Universidad de Antioquia, Medellín, \\ Colombia \\ ${ }^{3}$ Centro Avanzado de Diagnóstico Médico, CEDIMED, Medellín, Colombia \\ Las imágenes de resonancia magnética potenciadas en difusión y tractografía pueden emplearse en \\ el estudio de las malformaciones congénitas del sistema nervioso central asociadas a anormalidades \\ en los tractos de sustancia blanca. \\ Presentamos un paciente con holoprosencefalia semilobar en quien la imagen potenciada en difusión \\ y la tractografía demostró falla de la inducción ventral del prosencéfalo y fusión anormal de varios \\ fascículos de la sustancia blanca en el cerebro y en el tallo encefálico. De esta forma, las anormalidades \\ de los fascículos de la sustancia blanca en casos de holoprosencefalia se pueden identificar por medio \\ de las imágenes potenciadas en difusión y tractografía fasciculografía.
}

Palabras clave: espectroscopia de resonancia magnética, imagen de difusión por resonancia magnética, imagen de difusión tensora, anisotropía, holoprosencefalia, sustancia gris periacueductal, insuficiencia de crecimiento.

Clinical application of diffusion tensor imaging and tractography in a child with holoprosencephaly

Diffusion tensor imaging and fiber tracking can be methods used for the study of congenital brain malformations associated to white matter bundle abnormalities. Their use is illustrated in a child with semilobar holoprosencephaly in whom diffusion tensor imaging and tractography showed diencephalic ventral induction failure and abnormal white matter fascicles in brain and brainstem.

Key words: Magnetic resonance spectroscopy, diffusion magnetic resonance imaging, diffusion tensor imaging, anisotropy, holoprosencephaly, periaqueductal gray, failure to thrive.

Las imágenes potenciadas en difusión y las generadas con alta resolución angular (HighAngular-Resolution Diffusion Imaging. HARDI) son técnicas de imagen relativamente novedosas en resonancia magnética (1), en las que el contraste lo proporciona la anisotropía de difusión, es decir, el movimiento direccional preferencial inherente del agua dentro del cerebro (2).

Las imágenes potenciadas en difusión muestran la organización y arquitectura de la sustancia blanca, lo que no es evidente con la resonancia magnética convencional. Los datos se muestran como mapas de color (mapas de anisotropía fraccional), en los que el brillo representa la anisotropía de difusión y el color indica la orientación de los tractos o fascículos

\section{Correspondencia:}

Blair Ortiz, Calle 64 № 51D-154, Medellín, Colombia

Teléfono: (54) 444 1333, extensión 3325; fax: (54) 2637885

blairortiz@hotmail.com

Recibido: 09/08/10; aceptado:09/03/11
(3). La tractografía, fasciculografía, surge al seleccionar las fibras que tienen mínima anisotropía fraccional y definir una región de interés en los mapas; esta imagen en conformación tridimensional muestra las proyecciones de los axones.

La holoprosencefalia en una malformación compleja del prosencéfalo y de la sustancia blanca a diferentes niveles, que ocurre en las primeras cinco semanas de desarrollo embrionario; el $25 \%$ de los casos de holoprosencefalia corresponde a la forma semilobar (5). Entre el 24 y el $45 \%$ de los recién nacidos afectados por holoprosencefalia tienen anormalidades cromosómicas (5). Las imágenes potenciadas en difusión y la tractografía son una nueva herramienta para identificar las anormalidades de la sustancia blanca en las diferentes formas de holoprosencefalia (6).

\section{Presentación del caso}

Se trata de un paciente de sexo masculino de 11 años de edad, de raza blanca, con discapacidad 
cognitiva y parálisis cerebral. Los padres no eran consanguíneos y estaban sanos; fue su segundo hijo, y no se presentaron complicaciones durante el embarazo o el parto. Al nacimiento presentaba microcefalia, hipotonía, frente ancha, hipotelorismo, hipoplasia del tercio medio del rostro y un paladar arqueado pero íntegro. El cariotipo era $46 \mathrm{XY}$ y el estudio metabólico no reveló errores innatos. No había historia familiar de malformaciones congénitas ni problemas neurológicos.

Se solicitó y se obtuvo aprobación del Comité de Ética institucional para la realización del estudio. Para la adquisición de las imágenes, se empleó una unidad de resonancia magnética de 1,5-T. Las imágenes convencionales de resonancia magnética incluyeron secuencias sagitales, coronales y axiales potenciadas en T1, T2 e inversión de recuperación. Las imágenes potenciadas en difusión se obtuvieron a partir de una aplicación que permitía una toma de alta resolución angular. La tractografía se generó a partir del algoritmo de anisotropía fraccional y ubicando manualmente la región de interés en el cerebro y el tallo encefálico.

Las imágenes en $\mathrm{T} 1$ mostraron estructuras relativamente normales. No se identificaron fibras callosas (figura 1). Los núcleos caudados se dispusieron ventralmente a los tálamos. La neocorteza y la sustancia blanca ventral estaban fusionadas, sin encontrarse la fisura interhemisférica anterior. Sin embargo, la fisura interhemisférica posterior estaba presente. Las cisuras de Silvio estaban ubicadas en posición más medial y rostral de lo convencional; no se encontró globus pallidus ni claustrum. Los recesos frontales del ventrículo lateral estaban ausentes, dando una configuración monoventricular. El patrón de surcos era anormal en forma difusa, con paquigiria y heterotopias en la parte anterior. Los tálamos estaban parcialmente segmentados y los hipocampos incompletamente plegados.

En los mapas se encontró una estructura bilobulada subfrontal con haces de sustancia blanca orientados en forma transversa (figura 2); en la tractografía, los haces de color rojo indicaban fascículos con orientación preferencialmente transversa. Los haces córtico-espinales, de color azul, estuvieron ubicados detrás de los fascículos de sustancia blanca orientados en forma transversa. Las fibras de los fascículos fronto-occipital superior e inferior, estuvieron fusionadas y entrelazadas desde la parte más anterior. Aunque se encontró un esplenio, el cuerpo calloso era displásico en la parte rostral y el cuerpo.

La tractografía reveló fórnix displásico por su acortamiento en dirección antero-posterior, aunque mantuvieron la configuración normal en "C".

\section{Conclusiones}

Con la aparición de la resonancia magnética convencional, se caracterizaron mejor los detalles de las malformaciones inductivas de las tres capas germinales: endodermo, mesodermo y ectodermo
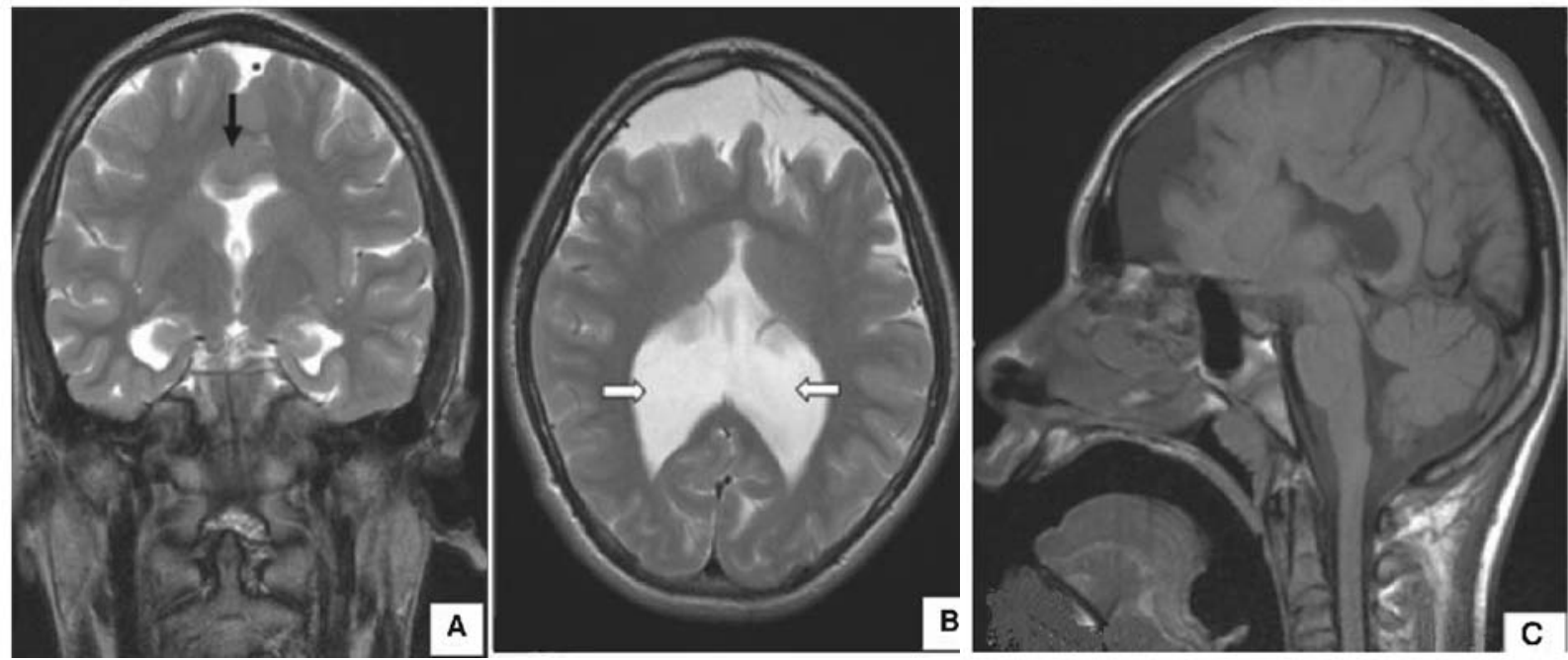

Figura 1. Imágenes de resonancia magnética en holoprosencefalia semilobar. A. Corte coronal T2 en el que se evidencia ausencia de fisura interhemisférica, fusión del tracto de la comisura en su parte anterior y heterotopia de sustancia gris subyacente (flecha). B. Corte transversal T2 en el que se encuentra monoventrículo (flechas), fusión del estriado y de la sustancia blanca en parte anterior. C. Corte sagital en T2 que muestra microcefalia, relación cráneo-facial alterada, disgenesia del cuerpo calloso y relativa normalidad de las estructuras infratentoriales. 


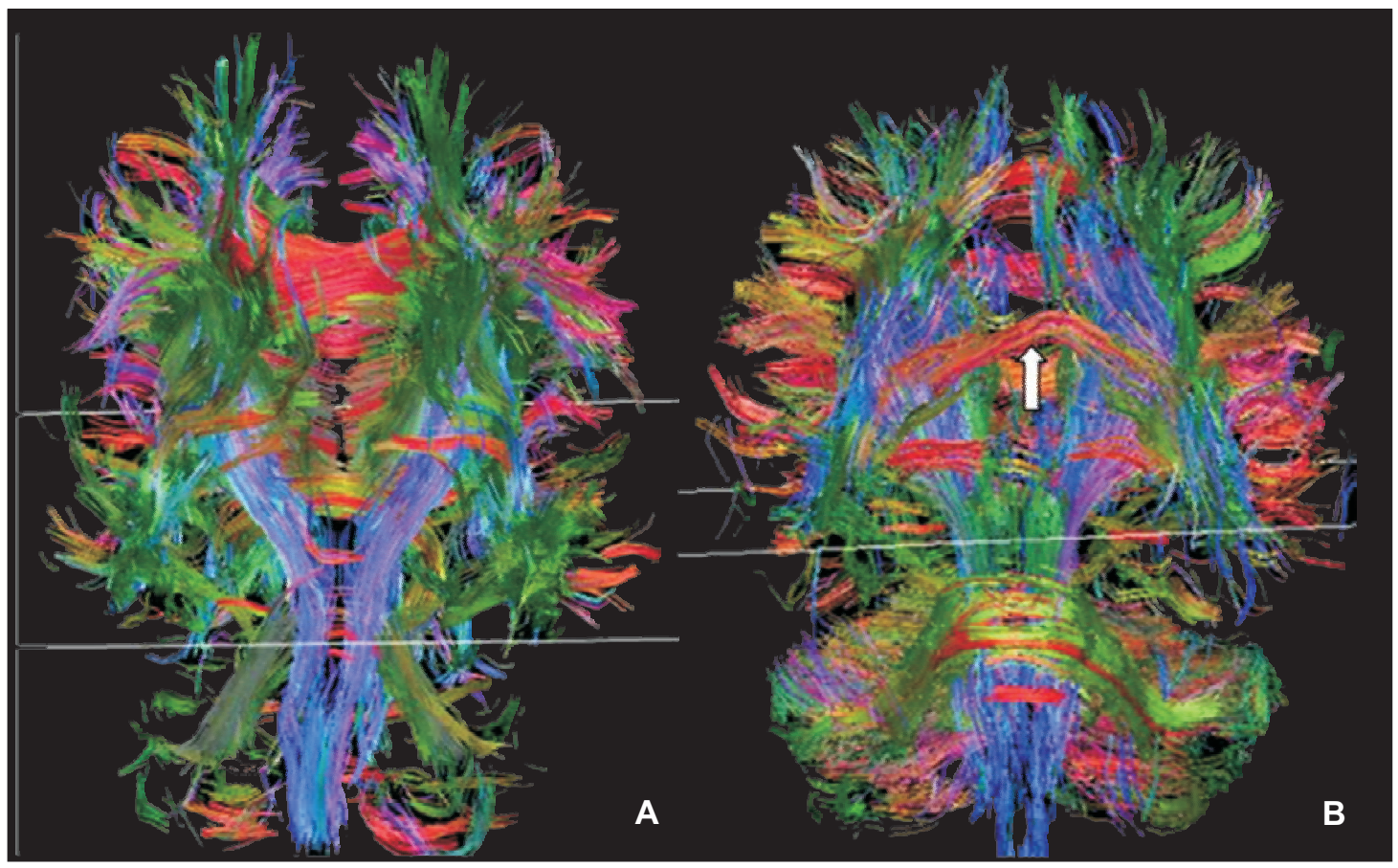

Figura 2. Tractografía. A. Vista anterior de un cerebro normal que muestra, en azul, los fascículos córtico-espinales descendiendo, en rojo, los fascículos de la comisura que cruzan de un lado al otro y, en verde, pequeños fascículos de asociación hemisférica. B. Imagen del aspecto anterior del encéfalo y tallo cerebral del paciente con holoprosencefalia, en la que se muestra orientación transversa de fibras de sustancia blanca en el lóbulo frontal (flecha) y falta de demarcación entre los fascículos longitudinal superior e inferior.

(7). En los estudios rutinarios de resonancia magnética, los hallazgos principales son la fusión o disposición anormal de la neocorteza, los núcleos caudados y el claustrum, así como la hipoplasia de los lóbulos frontales (8). Las consecuencias son más pronunciadas en la porción anterior del prosencéfalo y disminuyen en seriedad de la parte rostral a la caudal y de la medial a la lateral (9). La clasificación se hace de las formas menos graves a las más graves, como lobar, semilobar y alobar. En la variedad semilobar se preserva relativamente la parte posterior y lateral del cerebro, el esplenio, la fisura interhemisférica posterior y la hoz del cerebro; sin embargo, el ángulo silviano es amplio por hipoplasia frontal,del globus pallidus (8) y del brazo posterior de la cápsula interna, por fusión de los tálamos fusionados o por su posición más ventral (10) y por la displasia hipotalámica. Los fascículos de sustancia blanca no son aparentes en la resonancia magnética convencional.

Las imágenes potenciadas en difusión y la tractografía son las únicas herramientas disponibles para estudiar la sustancia blanca y sus conexiones; tienen enormes aplicaciones en el campo de las malformaciones congénitas del sistema nervioso central. En los mapas de las imágenes potenciadas en difusión, el color se emplea como un indicador de la orientación de las fibras (11).

En el estudio de las malformaciones e inmadurez del sistema nervioso central, los factores que permiten la adquisición de las imágenes potenciadas en difusión y la tractografía son los mismos que condicionan el grado de anisotropía. La sustancia gris posee un menor grado de anisotropía que la sustancia blanca. Los factores determinantes de la anisotropía de difusión son la hidratación tisular, la atenuación de la envoltura celular, el diámetro de las fibras, la atenuación de la envoltura de los axones, la actividad metabólica (transporte por los axones y flujos citoplasmáticos) y varias subestructuras de los axones (como membranas, microtúbulos, neurofilamentos y microfilamentos) (12).

En algunos pacientes con holoprosencefalia, los estudios de difusión revelan gran anisotropía fraccional de los núcleos caudados fusionados, debido a neuronas y axones con alto grado de apiñamiento (packing) (6). En nuestro paciente, los fascículos fronto-occipitales estaban fusionados en la mitad de la región subfrontal; encontramos pequeños fascículos orientados en forma transversa en la convexidad mayor de la sustancia blanca sin 
continuidad con los fascículos fronto-occipitales. Igual que lo reportaron Takahashi (9) y Probst (13), no encontramos el fórnix (trígono cerebral); más bien, los hallazgos de la tractografía demuestran que estas fibras permanecen en la pared de la holosfera dispuestas en el aspecto dorso-lateral y convergen hacia adelante y centralmente bajo la región septo-talámica, tras el cuerpo estriado. Esta descripción fue documentada por Yakovlev en estudios de especímenes patológicos (14).

En la holoprosencefalia puede encontrarse una amplia variabilidad en las anormalidades corticales. Mediante el estudio de difusión demostramos que las fibras córtico-espinales estaban en una localización ectópica por el curso ventral observado en la tractografía, cerca a una heterotopia de sustancia gris localizada en la región suprayacente al monoventrículo. Este hallazgo podría contribuir al curso dorsal de algunas fibras del brazo posterior de la cápsula interna evidenciadas en la tractografía. Aunque se observaron los tres pedúnculos cerebelosos, no podemos hacer una estimación objetiva de su tamaño. Por su parte, Albayram et al. describieron que el tamaño del pendúculo cerebeloso medio era directamente proporcional al grado de neurodesarrollo y dependiente del tipo de holoprosencefalia (4).

En nuestro paciente, la presencia de un esplenio calloso sugiere que la lámina de la comisura dorsal pudo formarse en ausencia de la rodilla y el cuerpo, pero sin lograr la configuración convencional que se encuentra en un cerebro normal.

En conclusión, ilustramos en un paciente holoprosencéfalico el estudio detallado de las malformaciones congénitas del sistema nervioso central mediante técnicas de difusión y tractografía que proveen una descripción más detallada de las anormalidades en los fascículos supratentoriales e infratentoriales de sustancia blanca, las que no pueden apreciarse en los estudios de resonancia magnética convencional. La rareza de este tipo de alteraciones dificulta hacer estudios de cohortes que permitan aclarar en forma sistemática si estos hallazgos pueden predecir el grado de neurodesarrollo y ayudar a la clasificación con base en la anatomía funcional (15).

\section{Conflicto de intereses}

Ninguno de los autores tuvo vinculación con alguna actividad que pudiera generar conflictos de interés.

\section{Financiación}

El desarrollo del artículo no contó con recursos de entidades nacionales ni internacionales.

\section{Referencias}

1. Ryuta I, Susumu M, Melhem ER. Diffusion tensor brain imaging and tractography. Neuroimaging Clin N Am. 2002;12:134-40

2. Dong $\mathrm{Q}$, Welsh RC, Chenevert TL, Dong Q, Welsh RC, Chenevert TL, et al. Clinical applications of diffusion tensor imaging. J Magn Reson Imaging. 2004;19:6-18.

3. Wakana S, Jiang H, Nagae-Poetscher LM, van Zijll PC, Mori S. Fiber tract-based atlas of human white matter anatomy. Radiology. 2004;230:77-87.

4. Albayram S, Melhem ER, Mori S, Zinreich SJ, Barkovich J, Kinsman SL. Holoprosencephaly in children: Diffusion tensor MR imaging of white matter tracts of the brainsteminitial experience. Radiology. 2002;223:645-51.

5. Raybaud C, Girard N. Malformations of the telencephalic commissures. In: Tortori-Donati $\mathrm{P}$, editor. Pediatric neuroradiology. Berlin: Springer; 2005. p. 41-69.

6. Rollins NK. Clinical applications of diffusion tensor imaging and tractography in children. Pediatr Radiol. 2007;37: 769-80.

7. Barkovich J. Magnetic resonance imaging: Role in the understanding of cerebral malformations. Brain Dev. 2002;24:2-12.

8. Barkovich AJ, Simon EM, Clegg NJ, Kinsman SL, Hahn JS. Analysis of cerebral cortex in holoprosencephaly with special attention to the sylvian fissures. AJNR Am J Neuroradiol. 2002;23:143-50.

9. Takahashi T, Kinsman S, Makris N, Grant E, Haselgrove C, Mclnerney S, et al. Semilobar holoprosencephaly with midline "seam": A topologic and morphogenetic model based upon MRI analysis. Cereb Cortex. 2003;13:1299-312.

10. Simon EM, Hevner R, Pinter JD, Kinsman S, Hahn $\mathbf{J}$, Barkovich AJ. Assessment of the deep gray nuclei in holoprosencephaly. AJNR Am J Neuroradiol. 2000;21: 1955-61.

11. DaSilva AFM, Tuch DS, Weigell MR, Hadjikhani N. A primer on diffusion tensor imaging of anatomical substructures. Neurosurg Focus. 2003;15:E4.

12. Mukherjee P, Miller JH, Shimony JS, Conturo TE, Lee BC, Almli CR, et al. Normal brain maturation during childhood: Developmental trends characterized with MR. Radiology. 2001;221:349-58.

13. Probst, FP. The prosencephalies: Morphology, neuroradiological appearances and differential diagnosis. New York, NY: Springer-Verlag; 1979. p. 35-64.

14. Yakovlev PI. Pathoarchitectonic studies of cerebral malformations. J Neuropathol Exp Neurol. 1959;18:22-55.

15. Wahl M, Barkovich J, Mukherjee P. Diffusion imaging and tractography of congenital brain malformations. Pediatr Radiol. 2010;40:59-67. 